\title{
NARRATIVAS DE ADOLESCENTES: UM CONVITE PARA CAPTAR SUBJETIVIDADES
}

\author{
SUSY CRISTINA RODRIGUES \\ Universidade Estadual de Campinas (Unicamp), \\ Campinas, São Paulo, Brasil \\ Áurea Maria GuImarães \\ Universidade Estadual de Campinas (Unicamp), \\ Campinas, São Paulo, Brasil
}

\begin{abstract}
RESUMO: Este artigo contribui com os estudos sobre violência e subjetividades no contexto da adolescência, por meio da discussão de resultados da metodologia do grupo focal com nove adolescentes que vivem na região do Campo Grande em Campinas, São Paulo (SP). Nesta pesquisa, as narrativas dos cotidianos dos adolescentes emitidos nos encontros do grupo focal se transformaram em uma história em quadrinhos, utilizando-se do recurso da transcriação. O artigo finaliza com as reflexões sobre a utilização do grupo focal como ferramenta favorável para captar mais do que narrativas e relatos do cotidiano, a saber, a memória, a expressão do pensamento, os valores, as resistências, as táticas e a peculiaridade das relações expressas em grupo, em suas múltiplas subjetividades.
\end{abstract}

PalavRas-Chave: Narrativas. Adolescentes. Subjetividades. Grupo focal.

INTRODUÇÃO

Este artigo retorna às pegadas iniciais do trajeto percorrido na pesquisa de campo, com a pretensão de contribuir para os estudos com as temáticas do grupo focal, violência, juventude e subjetividades. Expressa-se aqui, como ocorreu o processo da metodologia empregada, as dificuldades 
encontradas, os desafios e reflexões, valendo-se do grupo focal como estudo exploratório e complementar à história oral de vida de nove adolescentes de 12 a 14 anos, que vivem na região do Campo Grande, em Campinas, SP.

O cenário da pesquisa é constituído de violências e embora a região geográfica do Campo Grande tenha se expandido por estar em um processo constante de urbanização, ainda são visíveis a ineficiência de políticas públicas, a propagação da vulnerabilidade social ${ }^{1}$, bem como situações de risco pessoal e social.

O interesse desta pesquisa parte do pressuposto de ler o cotidiano da realidade social de alguns bairros ${ }^{2}$, que compõe a região do Campo Grande a partir das expressões relatadas pelos sujeitos escolhidos para participar deste estudo. Esta leitura vem de encontro com as reflexões sobre como os adolescentes sobrevivem nestes territórios vulneráveis. Quais são suas escolhas? Quais são suas formas de resistir, considerando as esferas sociais e coletivas? Existem enfrentamentos ou táticas para sobreviver?

Partindo destes questionamentos, ao coletar narrativas, relatos e opiniões no grupo focal, aproveita-se a oportunidade de perceber que as subjetividades de cada adolescente se expressam em um contexto específico de exclusão social permitindo fazer um percurso nessas trajetórias de vida, tendo como desdobramentos, as lutas, as estratégias, as resistências ante as contradições, tensões e conflitos enfrentados em seus cotidianos.

\section{UMA EXPERIÊNCIA COM O GRUPO FOCAL}

Optar pelo grupo focal no início da pesquisa teve como premissa conhecer preliminarmente o território e seus sujeitos, seus estilos de vida e códigos de comunicação, tendo um cuidado permanente em não deixar que a interpretação da pesquisadora interferisse nas relações sócias promovidas no grupo, como sugere Weller (2006, p. 241). Como não possuía vínculos de amizade e confiança com os adolescentes, essa ferramenta metodológica permitiu a aproximação com os sujeitos da pesquisa, ao privilegiar as trocas e interações nos diálogos entre o grupo.

Sendo facilitadora do grupo, a pesquisadora não interveio com suas próprias opiniões, fazendo apenas os encaminhamentos para direcionar o tema discutido, como aprecia Gatti $(2005$, p. 9). O grupo focal, enquanto técnica de levantamento de dados favorece às trocas de opiniões e à interação social dos participantes, e segundo Gatti $(2005$, p. 8$)$, vale ressaltar que o 
princípio da não diretividade deve ser respeitado, ou seja, o pesquisador, na qualidade de moderador não interfere na discussão do grupo.

Consideramos o grupo focal como uma lupa, capaz de captar vivências e relatos de experiências que muito provavelmente não viriam à tona, se não fosse a participação e a expressão do pensamento em um grupo. Ressalva-se essa percepção, pelo fato de que posteriormente, quando os adolescentes escutaram as narrativas de suas histórias individualmente, não houve tanta facilidade na exposição dos relatos, comparado ao momento em que os adolescentes expressaram-se no coletivo, em grupo. Apenas com a pesquisadora e com um gravador, na maior parte dos casos (sete adolescentes) houve uma dificuldade para desenvolver uma comunicação fluida, natural e livre.

A participação no grupo focal foi possível pelo convite voluntário, realizado em junho de 2013, na própria instituição de educação não escolar, situada na região Noroeste de Campinas, SP. O CECOMPI (Centro Comunitário da Criança do Parque Itajaí I e região) foi a instituição escolhida, localizada no bairro Parque Itajaí, existente desde 1989, e que atende crianças e adolescentes de seis a 14 anos de idade.

O critério de seleção dos adolescentes foi a idade, privilegiando os mais velhos. Foi realizado um convite para todos os adolescentes de 12 a 14 anos, totalizando 28, dos quais dez decidiram participar da pesquisa voluntariamente, dois meninos e oito meninas. Uma das meninas se mudou da região e participou apenas do primeiro encontro. Nos outros encontros, todos os adolescentes estavam presentes.

Os pais dos sujeitos da pesquisa assinaram o Termo Livre de Consentimento Esclarecido, autorizando a participação voluntária de seus filhos, a gravação do áudio para posterior transcrição dos encontros, estando cientes dos riscos, benefícios e vantagens na participação do estudo ${ }^{3}$. Todos os sujeitos da pesquisa estão matriculados na educação formal e frequentam diariamente o CECOMPI, no contra turno escolar.

É importante ressaltar que as expressões deste grupo de adolescentes não podem ser consideradas definitivas, dado que estas foram manifestadas em um contexto específico, entre os membros deste grupo.

As discussões do grupo focal não podem ser consideradas como um representativo do universo dos sujeitos pertencentes à instituição de educação não escolar, ou ainda dos adolescentes que vivem em situação de exclusão social, pois pretende captar as interações coletivas das singularidades expressas em múltiplas subjetividades, possibilitadas neste trabalho. Esta representatividade por tipologias, tais como gênero, geração, meio social, for- 
mação educacional, entre outras, são aprofundadas em grupos de discussão e não em grupo focal, pois nesta outra abordagem metodológica se trabalham com amostras e com análise comparativa (WELLER, 2006, p. 246-248).

Não nos detivemos em estabelecer roteiros fixos e rígidos para o planejamento do grupo focal, pois preferimos deixar o grupo mais à vontade possível, para que os relatos fluíssem o mais próximo de uma maneira natural.

Para este trabalho, os temas foram propostos para dar início aos diálogos, tendo utilizado muitas dicas na operacionalização do grupo focal, inspiradas no trabalho de Batista (2011). Segue a seguir a maneira como foram organizados os encontros:

Primeiro encontro: "conflitos"; recurso estimulante: filme "Escritores da Liberdade" (2007); duração: uma hora e meia; dez participantes;

Segundo encontro: "conflitos e regras"; recurso estimulante: desenhos e relatos por escrito; duração: 50 minutos; nove participantes;

Terceiro encontro: "resolvendo conflitos"; recurso estimulante: dinâmica com letras de músicas; duração: 50 minutos; nove participantes;

Quarto encontro:"confraternização e reflexão"; recurso estimulante: devolutiva com história em quadrinhos; duração: 50 minutos; nove participantes.

De fato, houve imprevisibilidade neste grupo, pois logo no início, as discussões foram pautadas com bastante engajamento. As expectativas lançadas para o primeiro encontro foram o inverso do ocorrido: pensava-se de que forma trabalhar com os possíveis momentos de silêncios. Contudo, não houve silêncios.

No primeiro encontro, foi exibido o filme "Escritores da liberdade" (2007). Antes de assistir o filme, foi solicitado que os adolescentes fizessem o exercício de refletir sobre situações que envolvessem conflitos em suas vidas, ou na vida de colegas, da família, enfim, de pessoas que conheciam.

Após o filme, foi surpreendente a gama de narrativas proferidas no encontro: houve vasta interação entre o grupo durante trinta minutos, na qual foram propiciados diálogos e complementaridade nas falas. O grupo demonstrou intimidade e sintonia, não sendo necessária a intervenção para fazer perguntas ou para retomar o foco do que estava sendo dito. Não houve dificuldade para se comunicar, pelo contrário, disputavam para falar e se não houvesse a limitação do tempo, talvez se expressassem muito mais. Três dos nove participantes ficaram observando a discussão, mas demonstravam a 
sua opinião, aprovando ou não o que se discutia, por meio de olhares que se entrelaçavam com sorrisos. Houve a tentativa de trazer estes três adolescentes para os diálogos, quando se captava esses sorrisos e olhares, perguntando o que eles pensavam sobre os relatos e opiniões emitidos, mas talvez pela timidez, ou por ainda não ter estabelecido um vínculo, não houve sucesso.

No segundo encontro, foi proposto o desenho e os relatos por escrito, justamente na tentativa de fazer com que os mais tímidos participassem falando, pois ao final da atividade, foi solicitado que o grupo socializasse suas escolhas, verbalizando-as. Apenas três participantes desenharam e os outros descreveram brigas na escola com outros colegas ou conflitos no ambiente familiar, envolvendo violência física.

O maior desafio foi conter a dispersão dos adolescentes no terceiro encontro: talvez a "falha" tenha ocorrido por ter estimulado os sujeitos da pesquisa com algo que lhes é muito caro: o funk. Todos começaram a cantar as músicas em voz alta, com entusiasmo e empolgação, demonstrando muita familiaridade com aquele universo. Neste encontro percebemos um esgotamento dos assuntos, finalizando-se neste momento, as atividades.

Pelo intervalo das atividades do grupo focal ter sido quinzenal, foi criado um perfil no Facebook ${ }^{4}$ para adicionar os participantes e evitar o risco de não conseguirmos criar um vínculo de confiança e também para proporcionar a observação do dia a dia "virtual" dos adolescentes sem estar junto deles. Tal ação se deu especificamente apenas para conhecer as relações sociais entre os membros do grupo no mundo virtual. O grupo aceitou o"pedido de amizade" da pesquisadora e ficou claro que o objetivo desta ação foi apenas para conhecê-los melhor, possibilitando inclusive um contato mais pessoal com esses adolescentes. O funk, a religião e os laços de amizade entre os adolescentes foram as temáticas mais latentes observadas nas publicações on-line dos perfis, durante os meses de setembro e novembro de 2013 . $^{5}$

\section{SUBJETIVIDADES: TÁTICAS E RESISTÊNCIAS}

Durante os relatos, houve situações narradas em que os adolescentes estavam presentes ou cientes da história do outro, e isto foi perceptível pelo complemento das histórias contadas envolvendo a violência doméstica, como podemos observar a seguir:

Kleber: Em casa eu tenho que limpar tudo, fazer comida e deixar tudo em ordem, eu chego cansado da escola, vou para o Núcleo (se referindo à ins- 
tituição de educação não escolar) e ainda tenho que trabalhar em casa. Eu deito na cama muito cansado. Se eu não fizer, eu apanho.

Márcia: Eu já apanhei várias vezes do meu irmão e da minha mãe.

Julia: Eu também. Semana passada eu apanhei e tentei fugir para o Bassoli.

Kleber: Nossa, eu odeio minha vó, eu odeio meu padrasto. Só porque um dia ele me deu vinte reais minha mãe fica toda hora jogando na minha cara que eu tenho que gostar dele. Ele vem pra casa todo fim de semana, é horrível... Ele é folgado, minha mãe me obriga a limpar tudo, passou dois minutos está tudo sujo! Tem uma amiga da minha mãe que tá morando em casa, ela não ajuda em nada! Minha avó falou uma vez que queria me ver igual àquelas crianças da África...

Priscila: É verdade... Ela falou que queria ver ele todo mole na cama...

Kleber: É isso, ela queria me ver mole na cama... Minha avó já veio falar mal de mim na escola, no Núcleo, mas ela se ferrou, porque sou um bom aluno. Mas no dia que ela falou essas coisas pra mim, eu chorei muito, sou muito sentimental, achei que ia entrar em depressão. Eu queria fugir, eu odeio minha família...

(FONTE: Fragmento da gravação do primeiro encontro do grupo focal)

Percebemos a partir deste relato, a ligação que se enviesa na reprodução da violência, pois os adolescentes sofrem as violências e também relatam que agridem outras pessoas com violências. Em um dos momentos no grupo focal, ao narrar as brigas envolvendo agressões físicas protagonizadas por Kelly, o clímax da banalidade da violência foi atingido: os adolescentes se reconheciam nesta ação e todos participaram, demonstrando um estímulo intenso no sentido de querer reviver aqueles momentos tidos como vitoriosos nas "batalhas". Houve muita euforia e veio à tona o compartilhamento de situações nas quais venciam pela força e violência os chamados "cabulosos", gíria utilizada no grupo.

No último encontro do grupo focal, foi entregue aos adolescentes uma história em quadrinhos, baseada em suas narrativas, apropriando-se do conceito de transcriação, utilizado por Meihy (2008, p. 147) nos estudos em história oral, que "implica em ação criativa [...]. É lógico que transcriação não admite invenção de situações, apenas propõe clareza na exposição": 
O conceito de transcriação é uma mutação, "ação transformada, ação recriada" de uma coisa em outra, de algo que, sendo de um estado de natureza se torna outro. A beleza da palavra composta por "trans" e "criação" sugere uma sabedoria que ativa o íntimo do ato de transcriar. Fala-se de geração, mas não de cópia ou reprodução. Nem de paródia ou imitação. [...] (MEIHY, 2008, p. 133).

A voz destes adolescentes foi potencializada por história em quadrinhos: esses meninos e meninas se reconheceram no enredo e perceberam que ao ver suas vozes dramatizadas no desenho, puderam transitar do silêncio ou do despercebimento de suas vozes para a expressão delas.

Após a leitura da história em quadrinhos ${ }^{6}$, foi perguntado aos adolescentes se já haviam parado para pensar sobre os acontecimentos da vida cotidiana, com o intuito de reflexão sobre seus significados na vida. As respostas foram negativas, em tom fatalista ao mesmo tempo em que também trouxe um despertar para a possibilidade de serem ouvidos:

Alice: "Minha vida é um inferno!"

Kleber: “Puxa, o diálogo não resolve nada...”

Julia: "Muito realista essa história em quadrinhos! Não temos o que fazer. É melhor ficar no quarto chorando."

Kleber: "Já pensei várias vezes, mas não adianta pensar, eu só sei falar gritando e isso não resolve nada."

Kelly: "Você viu aquela hora que passou o tio do Kleber tirando a faca dele? Muito legal mesmo!"

Kleber: "Vou levar a história em quadrinhos para minha mãe!! Para ela ver que é verdade!"

Luana:"Eu também vou mostrar pra minha mãe! Ela vai ver que o funk não é o fim do mundo e que faz parte de nossa realidade."

Priscila: "Eu também!"

Ricardo: “O Bassoli está muito real aqui..."

(Fonte: Fragmento da gravação do último encontro do grupo focal) 


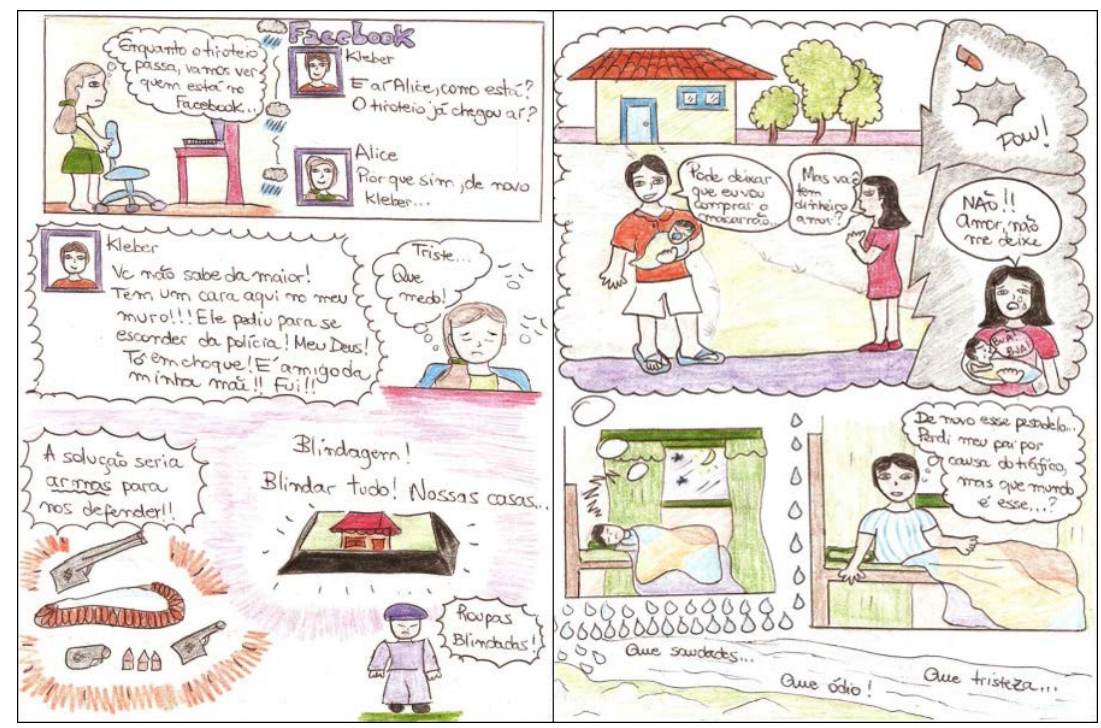

Figura 1 - parte da história em quadrinhos produzida pela pesquisadora.

Mas qual foi o conteúdo captado no grupo focal? Relatos detalhados de eventos da vida cotidiana dos adolescentes, envolvendo questões relacionadas principalmente à violência, criminalidade e preconceito.

O medo e a tristeza foram os sentimentos mais nítidos durante o grupo focal. Contudo, o funk pareceu ser um caminho propiciador de extroversão, alegria e extravasamento, que ao mesmo tempo pareceu destoar da autocensura e censura dos outros adolescentes, envolvidos com a religião. Conforme Dayrell (2002, p. 132) escreve sobre a dimensão da alegria e da socialização encontrada nos bailes funk, concordo que essa experiência leva os adolescentes a explorarem as possibilidades de reinventar-se na vida, aceitando-a como ela é, aproveitando e valorizando os momentos de trocas coletivas:

Podemos dizer que o baile funk representa, antes de tudo, a celebração da amizade, o espaço por excelência para viverem dimensões constitutivas da condição juvenil: a explosão emocional da alegria, a identificação coletiva, o sentir-se em grupo. Vianna (1987, p. 58) reforça essa dimensão ao afirmar que "as pessoas frequentam o baile não por um tipo de música, mas principalmente pelo ambiente, isto é, as outras pessoas, os amigos que se encontram e se divertem juntos, a alegria de viver em bando". Dessa forma, 
o baile funk constitui um espaço de sociabilidade, uma massa composta por grupos de amigos e galeras.

Enfatiza-se aqui, as percepções captadas na pluralidade das narrativas dos adolescentes, construídas coletivamente no grupo, em formato de sentimentos, gestos e expressões, elencados no formato de um rizoma (DELEUZE; GUATTARI, 1995, p. 11-37), cuja multiplicidade possibilita experimentar diferentes modos de se relacionar com o mundo, de fazer rupturas, e abrir caminhos para além de uma vida concebida enquanto fatalidade.

Estes autores deslocaram o conceito de rizoma da botânica para a filosofia: na botânica, o rizoma é um caule subterrâneo no todo ou em parte e de crescimento horizontal, segundo o dicionário Michaelis. É uma espécie de raiz, diferente do modelo de raiz tradicional que conhecemos. Para Deleuze e Guattari, um rizoma não é um conjunto de linhas exato, mas contém elementos vagos e nômades, como vemos na figura 2 .

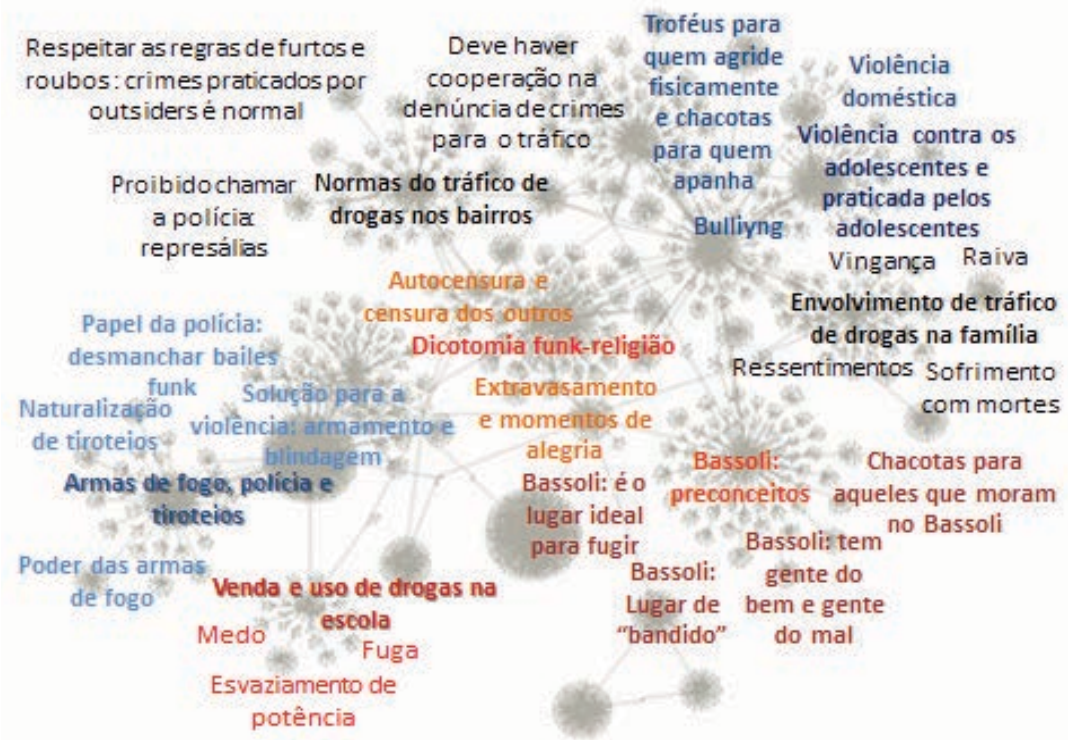

Figura 2 - rizoma do grupo focal mostrando a multiplicidade das narrativas (elaboração própria). 
Como estamos tratando de narrativas, a memória é entendida aqui enquanto "um dos suportes das múltiplas formas de existência do presente, permitindo a continuação que reproduz as condições de vida, o equilíbrio e as referências grupais" (CALDAS, 1999, p. 62). Ao unirmos esses elementos ao conceito de rizoma, parece ficar mais clara a multiplicidade de subjetividades encontradas no grupo focal, imersas na figura de um rizoma:

O pensamento não é arborescente e o cérebro não é uma matéria enraizada nem ramificada. [...] É mais uma erva que uma árvore. [...] Neurólogos e psicofisiólogos distinguem uma memória longa e uma curta, da ordem de um minuto, e sua diferença não é somente quantitativa. A memória curta é do tipo rizoma, diagramática, enquanto que a longa é árvore - centralizada. A memória curta pode ir e voltar em questão de momentos ou minutos, é descontínua, faz rupturas e opera por descontinuidade. As memórias não são tipos temporais diferentes de apreensão da mesma coisa, não são as mesmas ideias que apreendem, nem a mesma recordação (DELEUZE; GUATTARI, 1995, p. 23-24).

E como bem escreveu Michel de Certeau (1994, p. 38), "o cotidiano se inventa com mil maneiras de caça não autorizada". Isto quer dizer que ao viver experiências neste cotidiano repleto de situações adversas e invasivas configuradas pelas violências, podemos notar que os adolescentes sobrevivem e resistem neste contexto inóspito.

As táticas são práticas que consistem em desvencilhar-se dos efeitos do poder oriundos de instituições ou pelos "dispositivos que vampirizam as instituições e reorganizam clandestinamente o funcionamento do poder". As táticas seriam definidas pela vitória do fraco, fazendo uso de forças que Ihe são estranhas (CERTEAU, 1994, p. 41-47). Uma das táticas utilizadas pelos meninos e meninas desta pesquisa é utilizar-se da força que existe no bairro Bassoli como instrumento de fuga: ao mesmo tempo em que este bairro e a maior parte das pessoas que lá vivem são marginalizadas e rotuladas como pertencentes ao mundo do crime. Dessa forma, nos momentos de conflitos e tensões, a saída pode ser a idealização de "fugir para o Bassoli", mesmo que tal ação não se concretize.

Existem formas de resistir, que nos termos de Foucault, pode designar a possibilidades de liberdade e transformação:

Digo que a governabilidade implica a relação de si consigo mesmo, o que significa justamente que, nessa noção de governabilidade, viso ao conjunto das 
práticas pelas quais é possível constituir, definir, organizar, instrumentalizar as estratégias que os indivíduos, em sua liberdade, podem ter uns em relação aos outros. São indivíduos livres que tentam controlar, determinar, delimitar a liberdade dos outros e, para fazê-lo, dispõem de certos instrumentos para governar os outros. Isso se fundamenta então na liberdade, na relação de si consigo mesmo e na relação com o outro (FOUCAULT, 2006, p. 286).

O funk pode ser uma das maneiras de lutar contra os efeitos do poder, no sentido de ser um instrumento coletivo. Apesar de ser um estilo musical marginalizado, o funk demonstrou ser uma válvula de resistência viva no cotidiano dos adolescentes.

Ancorando-nos em Foucault, ao pensarmos nas relações de poder na família, na escola, enfim, em quaisquer relações humanas que atravessam as vidas destes adolescentes, podemos fazer a associação em que, onde há relações de poder

[...] há necessariamente possibilidade de resistência, pois se não houvesse possibilidade de resistência - de resistência violenta, de fuga, de subterfúgios, de estratégias que invertam a situação -, não haveria de forma alguma relações de poder (FOUCAULT, 2005, p. 276-277).

De posse dos relatos dos adolescentes que participaram dessa pesquisa podemos estabelecer uma ligação de resistências quando principalmente esses são expostos às situações conflituosas no âmbito das relações sociais cotidianas. Conforme esses relatos, as relações de violências não são vistas pelos adolescentes com naturalização, havendo enfrentamentos, ou ao menos, o desejo de que tenham mudanças em relação a essas situações vividas. Podemos ainda visualizar fatalismo, pessimismo ou ainda o desinteresse em pensar sobre tais mudanças, contudo, chamo a atenção aqui para a potência das vozes desses narradores, enfatizando a capacidade de resistir, como Foucault (2006, p. 232) afirma:

Quero dizer que as relações de poder suscitam necessariamente, apelam a cada instante, abrem a possibilidade a uma resistência, e é porque há possibilidade de resistência e resistência real que o poder daquele que domina tenta se manter com tanto mais força, tanto mais astúcia quanto maior for a resistência.

Nesta pesquisa em específico, chamou minha atenção, o fato da instituição de educação não escolar possuir vínculos com a influência cristã, perpassando a própria educação das crianças e adolescentes: 
Desde que cheguei nesta instituição, percebi a influência cristã na educação dos sujeitos da pesquisa: antes de coletar os dados da pesquisa, participei da reunião de pais, na qual foram distribuídos para todos os participantes um livreto intitulado "O profeta Elias". Ao utilizar a sala de vídeo, vi DVDs de estórias bíblicas em cima de uma mesa. Perguntei aos adolescentes se eles assistiam àqueles vídeos e eles relataram que esta é uma das atividades desenvolvidas na instituição. Associei tal fato com a visão da instituição, que inclusive consta em seu blog: "A educação é a arte de comprometer a pessoa humana com a construção de si próprio e do mundo, segundo o projeto de Deus". (Relato do Diário de Campo da pesquisadora, registrado em 30 de agosto de 2013).

É sabido que o funk é condenável dentro da moral cristã, fato este narrado nas vivências dos adolescentes durante o grupo focal. Mas pensá-lo no contexto da religiosidade também mostra suas linhas de fugas ${ }^{7}$, como se fosse a figura de um camaleão, que ao mesmo tempo em que é reprimido, é um motor para extravasar, estreitar vínculos de amizade e atuar como uma válvula de resistência contra os problemas, principalmente, assumindo um caráter coletivo de significado épico, de superação e motivação.

Ressalta-se neste trabalho, relatos de embates, enfrentamentos como brigas na escola e revide contra a família em situações de conflitos, contendo violência física. No entanto, fica claro que em muitas situações, esses adolescentes demonstram que não estão dispostos a se submeterem, mas que sobrevivem, mesmo que seja com pequenos sucessos: eles "tem constantemente que jogar com os acontecimentos para os transformar em 'ocasiões.' " (CERTEAU, 1994, p. 47).

\section{CONSIDERAÇÕES FINAIS}

Desde o início desta pesquisa, a intenção de trabalhar com o cotidiano de adolescentes perpassou a sugestão de Pais (2003, p. 51): atuar como "pesquisador viajante":

Fazer sociologia do quotidiano é desenvolver essa capacidade de flâneur, de passeante "ocioso": daquele que se passeia por entre a multidão, misturando-se nela, vagueando ao acaso, sem destino aparente, no fluxo e refluxo das massas de gente e acontecimentos. Um pouco como acontecia com os impressionistas [...] sobretudo, na reação despreconceituada do artista perante a realidade para que a instantaneidade desta o pudesse impressionar. 
Ao trabalhar com o grupo focal, vislumbra-se a oportunidade de fazer bom uso das imprevisibilidades e da espontaneidade que ocorre nas narrativas de um grupo, que somadas ao Facebook nesta pesquisa, foi de fundamental valia para que fossem elucidados alguns "códigos" das linguagens, muitas vezes provenientes de letras de músicas de funk, bem como para conhecer as relações entre o grupo, as proximidades, os conflitos e as contradições.

Um dos pontos favoráveis das pesquisas que lidam com o cotidiano, é ver o diferente na repetição, desconstruindo os velhos paradigmas e rótulos; também faz vislumbrar os valores, as visões de mundo, as motivações, desmotivações, continuidades, rupturas. Ao pesquisar o cotidiano, podemos ver:

[...] as coisas reduzidas aos seus signos, os quais irrigam e avolumam as representações sociais, as visões do mundo. É esta natureza ideográfica do social que o leva a ter um caráter enigmático, bem evidenciado no seu duplo sentido: literal e secreto, visível e invisível, mundano e transcendente. A ambivalência da realidade social é, afinal, o fundamento da própria sociologia (PAIS, 2003, p. 55-56).

Pesquisar subjetividades e violências mostra as diversas possibilidades de destruir velhas certezas e enxergar outros modos de viver. $O$ trabalho com as narrativas implica também em sentir e se aproximar do cotidiano do outro, potencializando a voz dos sujeitos da pesquisa.

\section{ADOLESCENTS' NARRATIVES: AN INVITATION TO CAPTURE SUBJECTIVITIES}

ABSTRACT:This paper contributes to studies on violence and subjectivities in the context of adolescence, through the medium of discussion of results about the methodology of the focus group with nine teenagers who live in the Campo Grande region, in Campinas, SP. In this research, the narratives of adolescents' daily lives told in the focus group meetings have turned into a comic strip, using the resource of transcreation. The article concludes with reflections on the use of the focus group as a favorable tool to capture more than narratives and stories of everyday life, such as memory, expression of thought, morals, strengths, tactics and the peculiarity of the relations expressed in groups, in their multiple subjectivities.

KEYworDs: Narratives. Adolescents. Subjectivities. Focus group. 


\section{NARRATIVA DE ADOLESCENTES: UNA INVITACIÓN PARA CAPTURAR SUBJETIVIDADES}

RESUMEN: Este artículo contribuye con los estudios sobre la violencia y subjetividades en el contexto de la adolescencia, a través de la discusión de los resultados de la metodología de grupo focal con nueve adolescentes que viven en la zona de Campo Grande, en Campinas, SÃO PAULO. En esta investigación, los relatos de los cotidianos de los adolescentes participantes en las reuniones de los grupos focales se han convertido en un libro de historietas, utilizando la transcripción. El artículo concluye con reflexiones sobre el uso de grupos de enfoque como herramienta favorable para captar más de que las narraciones e historias de la vida cotidiana, es decir, la memoria, la expresión del pensamiento, valores, fortalezas, las tácticas y la peculiaridad de las relaciones expresadas en el grupo, en sus múltiples subjetividades.

Palabras clave: Narrativas. Adolescentes. Subjetividades. Grupo focal.

\section{NOTAS}

1) De acordo com a Política Nacional de Assistência Social (PNAS), vivenciar situações de vulnerabilidade social inclui aqui: “[...] perda ou fragilidade de vínculos de afetividade, pertencimento e sociabilidade; ciclos de vida; identidades estigmatizadas em termos étnico, cultural e sexual; [...] exclusão pela pobreza e, ou, no acesso às demais políticas públicas; [...]". Já as situações de risco pessoal e social podem ser exemplificadas em: "abandono, maus-tratos físicos e, ou, psíquicos, abuso sexual, uso de substâncias psicoativas, cumprimento de medidas socioeducativas, situação de rua, situação de trabalho infantil, entre outras." (PNAS, 2004, p. 33-34).

2) Os bairros são: Santa Clara, Parque Itajaí, Parque Floresta, São Bento, Residencial Bassoli e São Luíz.

3) A gravação em áudio dos encontros do grupo focal funcionou como suporte para a pesquisadora realizar o trabalho de sistematização da coleta de dados e para obtenção de resultados da pesquisa, sendo utilizada apenas para este fim, não considerando, portanto, o seu arquivamento. Por questões éticas, todos os nomes dos participantes dessa pesquisa descritos aqui são fictícios.

4) Somos muito gratas à professora Dra. Dirce Zan que sugeriu ousadamente à pesquisadora criar um perfil no Facebook, especificamente para comunicar-se com o grupo.

5) Esta modalidade de experiência de campo não pode se confundir com observação, e recentemente ainda há poucos estudos sobre a netnografia. Conferir os trabalhos de Howard (2002) e Noveli (2010). 
6) Por ter uma preocupação em apresentar uma devolutiva aos adolescentes ao final deste trabalho, e por perceber que houve uma dificuldade no exercício de abstração dos adolescentes nas reflexões propostas no decorrer dos encontros, enquanto pesquisadora, criei uma história em quadrinhos, apostando na ênfase da característica do hipervisual que atravessa as relações sociais deste século, conforme bem analisa Aguayo e Roca (2005, p. 9). Inicialmente, minha orientadora, Dra. Áurea M. Guimarães, sugeriu transformar o conteúdo narrado pelos jovens no grupo focal em um conto. Por fim, acabei escrevendo uma crônica que consta em minha dissertação, mas que foi melhor retratada no desenho, a partir da história em quadrinhos.

7) "A linha de fuga é uma desterritorialização. Os franceses não sabem bem do que se trata. Evidentemente, eles fogem como todo mundo, mas acham que fugir é sair do mundo, mística ou arte, ou então que é algo covarde, porque se escapa aos compromissos e às responsabilidades. Fugir não é absolutamente renunciar às ações, nada mais ativo que uma fuga. É o contrário do imaginário. É igualmente fazer fugir, não obrigatoriamente os outros, mas fazer fugir algo, fazer fugir um sistema como se arrebenta um tubo... Fugir é traçar uma linha, linhas, toda uma cartografia." (DELEUZE e PARNET, 1998, p. 47).

\section{REFERÊNCIAS}

AGUAYO, F.; ROCA, L. (Coord.). Imágenes e investigación social. México: Instituto Mora, 2005.

BATISTA, E. H. de M. Bullying e as diferenças: a busca por um olhar ampliado. Dissertação (Mestrado em Educação) - Faculdade de Educação da Universidade Estadual de Campinas, Campinas-SP, 2011.

BRASIL. Política Nacional de Assistência Social. Ministério do Desenvolvimento Social e Combate à Fome: Brasília, 2004.

CALDAS, A. L. Oralidade, texto e história: para ler a história oral. São Paulo: Loyola, 1999.

CECOMPI. Centro Comunitário da Criança do Parque Itajaí. Disponível em: <http:// cecompi.wordpress.com/2009/08/06/hello-world/>. Acesso em: 19 nov. 2013.

CERTEAU, M. de. Artes de Fazer e Fazer com: usos e táticas. In: A invenção do cotidiano. Rio de Janeiro: Vozes, 1994. p. 35-106.

DAYRELL, J. O rap e o funk na socialização dos jovens. Educação e Pesquisa, São Paulo, v.28, n.1, p. 117-136, jan./jun. 2002. Disponível em: <http://www.scielo.br/pdf/ep/ v28n1/11660.pdf>. Acesso em: 17 jun. 2014.

DELEUZE, G.; GUATTARI, F. Mil Platôs: capitalismo e esquizofrenia. 1. ed. v. 5. São Paulo: Editora 34, 1997. 
. Mil Platôs: capitalismo e esquizofrenia. v. 1. Rio de Janeiro: Editora 34, 1995.

DELEUZE, G.; PARNET, C. Diálogos. Tradução Eloisa A. Ribeiro. São Paulo: Editora Escuta, 1998.

FOUCAULT, M. A ética do cuidado de si como prática de liberdade. In: Ditose Escritos IV: estratégia poder-saber. Tradução de Elisü Monteiro, Inês Autmn Dourado Barbosa. 2. ed. Rio de Janeiro: Forense Universitária, 2006. p. 264-287.

Polêmica, política e problematizações. In: Ditos e Escritos IV: Estratégia Poder-Saber. Tradução de Elisü Monteiro, Inês Autmn Dourado Barbosa. 2. ed. Rio de Janeiro: Forense Universitária, 2006. p. 225-233.

GATTI, B. A. Grupo Focal na pesquisa em Ciências Sociais e Humanas. Brasília: Líber Livro Editora, 2005.

HOWARD, P. Network Etnography and the Hypermedia Organization: new media, new organizations, new methods. New Media \& Society, University of Illinois, v. 4, n. 4, p. $550-574$, december/2002.

MAGALHÃES, V. B. de. Imigração, subjetividade e memória coletiva. ORALIDADES: Revista de História Oral, São Paulo, ano 1, n. 1, p. 23-33, jan./jun. 2007.

MEIHY, J. C. S. B. Palavras aos jovens oralistas: entrevistas em história oral. ORALIDADES. Revista de História Oral, São Paulo, ano 2, n. 3, p. 141-150, jan./jun. 2008.

NOVELI, M. Do off-line para o online: a netnografia como método de pesquisa ou o que pode acontecer quando tentamos levar a etnografia para a internet? Revista Organizações em Contexto, ano 6, n. 12, p. 107-133, jul./dez. 2010. Disponível em: <https://www.metodista.br/revistas/revistas-ims/index.php/OC/article/ view/2697/2640>. Acesso em: 16 jan. 2014.

PAIS, J. M. À descoberta dos enigmas do quotidiano. In: Vida cotidiana: enigmas e revelações. São Paulo: Cortez, 2003. p. 51-70.

WELLER, W. Grupos de discussão na pesquisa com adolescentes e jovens: aportes teórico-metodológicos e análise de uma experiência com o método. Revista Educação e Pesquisa, São Paulo, v. 32, n. 2, p. 241-260, maio/ ago. 2006.

\section{FILMOGRAFIA}

ESCRITORES da Liberdade. Direção: Richard La Gravenese, 2007. DVD (90 min). 
SUSY CRISTINA ROdRIGUES: Doutoranda em Educação pela Universidade Estadual de Campinas. Atualmente é assistente social no SAPECA (Serviço de Acolhimento e Proteção Especial à Criança e ao Adolescente) pela Prefeitura Municipal de Campinas, professora colaboradora na Pós-Graduação da FE/UNICAMP, professora de metodologia científica pela Tutores e pesquisadora do grupo de pesquisa VIOLAR estudos sobre juventude, imaginário e violência. No momento, pesquisa os seguintes temas: juventude, subjetividades, resistência, violência, periferias e exclusão social, cujo diálogo tem sido realizado com os autores Michel Foucault, Friedrich Nietzsche e Gilles Deleuze.

E-mail: susy_crs@yahoo.com.br

Áurea Maria Guimarães: Doutora em Filosofia e História da Educa ção pela Universidade Estadual de Campinas e livre docente pela Faculdade de Educação da Unicamp. Atualmente é Professora Associada I da Universidade Estadual de Campinas e pesquisadora do grupo VIOLAR: Laboratório de Estudos sobre Violência, Imaginário e Juventude, do Programa de Pós-Graduação da Faculdade de Educação da Unicamp. Tem experiência na área de Educação, atuando principalmente nos seguintes temas: educação, violência, escola, cultura e imaginário.

E-mail: auguima@yahoo.com.br 